\title{
Study on Design Elements of Residential Courtyard Environment
}

\author{
Weixiao Zhen ${ }^{1}$ \\ ${ }^{1}$ Hebei Academy of Fine Arts, Xinle, Hebei, 050700
}

KEYWORDS: Residential Courtyard; Application Standard; Design Elements

\begin{abstract}
With the development of society, people's living standards are improving, the quality of life is now more demanding applications indoor elements, resulting in a corresponding visual enjoyment. Social accelerating urbanization process, uniform standard of urban construction, so that high-rise buildings going up, people are increasingly eager hope it will return to the original state of life, environmental design elements of residential courtyard of the inside reference to the landscape design. Residential garden design environment is designed to fit people's lives in the state, serving the masses of people, only public recognition, be encouraged to continue development.
\end{abstract}

\section{What is the Residence Courtyard Environment Design}

Residential courtyard environment design within the scope of architectural design, and architectural decoration is an important part of the architecture. Architecture contains a lot of things, from the beginning of the nineteenth century, architectural decoration is synonymous with architecture, most architects think, decorative architectural art is the main difference with the simple design of the house. Industrial revolution and its change induced expansion of the connotation of the building, the concept of modern architectural design replaces the architectural decoration, this situation lasted until the 1970s. Now, a new awareness of the architectural inheritance in the construction of personalized, architectural traditions and meet the demand of public significance psychosocial aspects.

Since the reform and opening up, with the improvement of people's economic level, people of higher social level has been improved.

Architectural design not only consider the building as a matter of hexahedral, but the use of multi-disciplinary knowledge comprehensively carry out multi-level space environment design, the use of composing the plane and space, illusion, light, reflections and color changes such as the principle with the material means to create expected style and atmosphere. It includes a variety of residential outdoor courtyard design and environmental design decoration design and residential building environment design of residential and public buildings. Among them, the residential courtyard environment design is not just a simple decoration, it is not only beautify the general sense, it should be sufficient to meet the interior space of the nature and purpose, and with the construction features and construction techniques (style) to adapt through space, shape, detail, color, art, etc. comprehensive overall design, meet different functional and aesthetic value.

Interior design concept since China's reform and opening up has been used up to now, start simply paint the walls, and later began a beautiful indoor furniture layout, it is now related to the conversion and utilization of landscape factors aspects.

\section{The Landscape Elements in Housing Environment Design Garden Design}


Landscape elements from the reference design into the future, it has always been popular, most metropolitan inside buildings are reinforced concrete, the introduction of landscape elements beneficial to people to improve themselves, the current state of life.

Residential courtyard environment design fit the design needs of people living in the state, combined with people's needs, but also to reflect what we call "natural" sense, meet the demand for green environment, this aspect is not only at home, living environment, or in the office, learning environment, we occupy a very important position.

Now the high-paced society, people and the opportunity to make contact with nature is becoming less and less people away from the green environment, the introduction of interior design landscape elements needed just to meet people this piece.

Now people are missing something the city is most interior designers want to show to the people of a visual treat, factors into the landscape, the "natural" By design, concentrated to a small part of the show giving, people enjoy a better visual, busy life to make up for the lack of the environmental factors.

Now most people in modern residential building is not simply to meet the needs for survival, but for the quality is guaranteed, which requires interior design reflected, requiring indoor objects can be reflected the owner's taste, personality!

However, the overall design process residential courtyard environment, to show up is the overall harmony of the factors, but also on the inside of this harmonious factors show a better respect of individuals, for example, in an office environment inside, you can not have too many bright elements in it, and this would require most of the environmental factors of mutual integration.

Environment designer to residential courtyard design, the use of modern advanced scientific technology, residential courtyards of sound, light, color, shape can be the perfect combination, reflecting the natural beauty of the room harmony.

Many modern performance technology has been improved, some scenes simply design can reach the point of real ones, they will tend to ignore each other modern fusion with the surrounding environment, but with the accelerating pace of modernization, there is growing attention to environmental meet at the concept of the above factors change.

Modernization and transformation of the natural beauty of the combination is a win-win situation, to meet the needs of the people of the environment, an important factor to show the modern scene.

With the current level to improve the social life of people living on their own have become increasingly demanding environment, requirements reflect their own personality, especially in the introduction of foreign elements into the country began, there is growing attention to environmental changes above, this that I saw something reflected in the above aspects.

Set from the very beginning of the application of environmental factors, and now the technology is mature stage of transition, which is an image presented to design their own environment to see above the above factors change.

Groups landscape factors residential courtyard environmental design services, is the people of the public, this is beyond doubt. All residential courtyard environment originally designed, is to serve people's lives, it is referred to the special services in the design scene.

\section{The Function of Residential Courtyard in Environmental Design and Landscape Elements}

Interior Design There are six main landscape elements, namely: spatial scale elements, material components, fluid dynamic elements, functional elements, elements of spiritual needs, ecological elements. 
The six elements of the interior design has a decisive role, the use of these elements, can constitute a good indoor environment enables the design of residential courtyard environment more close to human, harmonization, naturalizing effect appears different designs.

Comparison of single metropolis inside the environment, but because of the reference to these factors, the environment as much as possible to achieve the design of the original intention of the people, the people desired effect.

Landscape design mainly plastic arts-based, so the design process can follow basic rules of formal beauty. Most of the elements of landscape design are derived from nature, from life, showing reflects the harmony is the key factor in terms of people and society.

Any shape of art follow the point is that forms can be varied, but the theme of the performance is the same. Overall art are made with small parts, and there is a linkage between these parts, they have differences. Typically residential courtyard interior landscape designer environmental design environment when these will form part of the follow certain rules put out, showing different visual effect, is what we call the principle of diversity and unity.

Green leaves lining the flowers, according to the theme of the factors, the elements required to summarize, then follow a certain element is formed to constitute the main body is formed with a secondary factor to bring out the theme, think of the effect is expected to achieve, which is the master-slave in principle.

Comply with the master-slave principle, in favor of highlighting the theme, show the advantages of the design environment and this is very important, use the above change of environment, the above factors change they can see.

For a design as a whole, there is not the lack of contrast is one of the factors. Contrast can cause changes in prominent a feature of a scene or a scene in order to attract people's attention, show a different perception of the beholder, is originally designed to be reflected, but should not be used too, it will be more contrast, otherwise there will be confusion vision, not prominent theme.

In contrast, people in favor of comparing conducive to change the traditional concepts, promote the development of environmental design of residential courtyard design, the use of factors relevant to the landscape, to create an environment to meet people and enjoy the visual.

Starting point for any design is to meet human need, all are in harmony with the landscape of the factors in it. Not too much personalization, harmonious. From the overall use of the above law, choice of materials is to be coordinated with the actual situation.

Mutual coordination, residential garden landscape elements need to select the entire environment and environment scene corresponding to coordinate with each other in a different environment and use different functions to adapt to different points of the environment. Factors taken landscape will be different. For example, in the company's office landscape is atmospheric environment, requirements, manifested refining, just inside the park scene is different performance, environmental theme park is to take the quiet, soft, comfortable space atmosphere, people feel relaxed .

In the design of the scene, it should be to follow the principle of harmony, to be more acceptable, so that more and more people, so eager to have a chance to get close to such an indoor environment.

Rhythm and rhythm in landscape design, often using point, line, surface, body, color and texture and other modeling elements to achieve rhythm and beat, so that the landscape has a sense of order, a sense of movement, reflected in the overall lively modeling.

Rhythm and beat of use, so that the full landscape design more in line with the above people's ideas change, the more harmonious people of integrity, so the landscape in line with people's ideas, fit people's actual results, even to the realistic effect. 
Proportion and scale in landscape design, implement the design using the ratio of the whole story, mainly in two aspects: one is a proportional relationship between the various components of the landscape and the part to the whole, on the other hand, is a landscape the proportion of each component part of the whole and partial, or the ratio between the local and the local, mainly referring to specific microscopic aspects of the design, more widely.

With this link, so that the overall environmental factors change, the better to show up more and more a state of the environment, so that the overall environmental design of residential courtyard design more fitting person's overall image of the above changes.

\section{Conclusion}

With the pace of China's modernization, more and more people began to shift from the idea of enjoying material life to the spiritual world to enjoy, more and more people begin to pay attention to the situation of their own living environment, such as their work environment, living environment, learning environment, like, look at all the interior design, are ultimately landscape factors, this is one of the essential elements.

Residential Environment courtyard design into landscape elements, the interior more than a touch of green light, the overall presentation of people feel comfortable, so that the overall phenomenon, manifested harmonious relationship between the characters. We can see a lot of environmental design of residential courtyard design is inseparable from this factor, such as the design of many inside the company environment is ultimately this factor.

Environmental design of residential courtyard in the public service is designed to meet the needs of the people living in the residential courtyard designer environmental design should be more close to life, and strive to build a people and society, as a whole a natural environment of mutual integration of man and nature are exhibiting It changes, showing change their environment.

With the above change people's ideas, accepting environment design of residential courtyard design, but also the prospect of environmental design of residential courtyard design direction of development of the profession, the application of landscape elements, environmental design of residential courtyard design, the essential key components.

\section{REFERENCE:}

[1] An Yuyuan; ecological adaptability Wang ;; Gannan Tibetan traditional houses of [A]; Architectural History and Theory eleventh series (Academic Symposium 2011 History of Chinese Architecture - Lanzhou University of Technology.Vol. 37 ); 2011.

[2] Liu Defeng. Lving for the extension of the built environment of urban history and culture [J]. Anhui Architecture; 2009-03.

[3] shall be Fan Zhuang, Hu Xiaoming; urban waterfront development Construction - In the Hangzhou West Hunan line Conformity project as an example [J]. Huazhong Architecture; 2003, 05.

[4] Li Xin. Rural Landscape Elements in shaping the Regional Cultural Landscape - A Case Study of Huangpu Village construction project [J]. Guangdong Forestry; 2011, 06.

[5] Zhao Yan. relations Bianguang Meng. commercial pedestrian street landscape elements and behavioral characteristics of [A]. Shao Long harmonious urban planning --2007 China Urban Planning Annual Conference Proceedings, 2007.

[6] Wang Jie; Protection and Utilization of the fishing village public space planning and design of local landscape elements [D], Zhejiang University of Technology; 2012. 
[7] Zhou Haomin. sustainable environmental design of residential courtyards organic integrity of (the) [J], China Construction News, 2012.

[8] Li Tingting; nursery garden environmental design of residential design research [D]. Jilin University; 2013.

[9] Wei Hing Fat; Wang Kunyu ;; garden green constructing new countryside harmonious cultural ecology livable environment research [A]; Tenth China Association for Science Symposium . 2008.

[10] Li Wei; Chen Qun Yuan. Changsha City Master Plan revision in the Landscape Conservation and Utilization of [A]. the new city planning under the guidance of research - - 2009 Town and Country Planning, Hunan Province outstanding Proceedings, 2009. 